\title{
Sri Lanka's Health Unit Program: A Model of "Selective" Primary Health Care
}

\author{
Soma Hewa
}

\section{Introduction}

Thirty years ago vigorous debates on primary health care articulated at least two main approaches to health promotion in developing countries. The Alma-Ata Declaration of the World Health Organization (WHO) kicked off the debate in 1978 by urging all nations to promote health through primary health care. Reaffirming the 1946 WHO charter that recognized health as a "state of complete physical, mental and social well-being," the Declaration recommended a comprehensive primary health care program, which included at least the following key sectors: "education to inform prevailing health problems and measures to control them, food security and improved nutrition, supply of clean water and sanitary services, maternal and child care services including family planning, immunization against communicable diseases, the control of locally endemic disease, and the supply of essential drugs for critical health problems." In allocating resources to these key sectors of the primary health care, the Declaration recommended, countries must ensure "equality," "affordability" and "community participation."

An alternative to this approach was promoted mainly by the representatives of the United States Agency for International Development, the Rockefeller Foundation and the World Bank who argued that comprehensive primary health care would be prohibitively costly to implement for most nations. ${ }^{2}$ One of the

1 World Health Organization, Primary Health Care. Report of the International Conference on Primary Health Care, Geneva, WHO, 1978. Also, see WHO, Targets for Health for All by the Year 2000, ALMA-ATA: WHO, Geneva, 1978.

2 M. Cueto, "The Origins of Primary Health Care and Selective Primary Health Care," American Journal of Public Health, 94, No.11, 2004, pp. 1864-1874. Analyzing the primary care model proposed by the Alma-Ata Declaration, and the institutional background of the personalities involved in this campaign, Cueto argues that the Declaration and the response it received were heavily influenced by Cold-War politics. 
leading critics of the comprehensive primary health care was Kenneth S. Warren, who spent a quarter of a century working as an expert on tropical medicine in Africa, Asia and Central America. Warren maintained that relatively inexpensive and "community based" primary health care could easily deal with

most widespread infectious diseases, and could substantially increase the life expectancy of millions of people in developing countries. ${ }^{3}$ Thus, he argued that a "state of complete physical, mental and social well-being is an unattainable ideal." He pointed to the fact that in developed industrialized countries, where physical wellbeing had improved, mental illness has risen considerably. Likewise, he argued, although social wellbeing had improved within and between nations in recent decades, the economic disparities have increased. ${ }^{4}$

In a paper, co-authored with Julia A. Walsh, Warren argued: "We believe that a selective attack on the most severe public health problems facing a locality should be considered in order for us to have the greatest chance to improve health and medical care in less developed countries." They called it an "interim strategy" for disease control in developing countries.

In order to formulate a clear-cut framework of selective primary health care, the Rockefeller Foundation sponsored a conference in 1979 titled, "Health and Population in Development." In summarizing the conference proceedings, David E. Bell, the vice president of the Ford Foundation, argued that several models of primary health care have been in operation in the global south for decades, which have "resulted in a remarkable reduction in infant and child mortality rates and increase in life expectancies."

The basic premise of the selective primary health care is that traditional indicators of health, such as infant mortality and life expectancy, are composites of many different health problems endemic to less developed countries. Some health problems are more serious than others in terms of their impact on mortality and morbidity. Thus, the selective primary health care listed infectious disease in the developing world in the order of their importance based on prevalence, mortality and morbidity, and the feasibility of effective control by using the available technology. It classified the diseases into three priority groups: high, medium and low. The diseases in the high priority group, for example, "represent infections causing the greatest amount of most easily preventable illness and death." The

3 K. S. Warren, "The Alma-Ata Declaration: Health for All by the Year 2000?" Britannica Book of the Year, Encyclopedia Britannica, Inc., Chicago, 1990, pp. 21-30. Warren served as the director of health services at the Rockefeller Foundation from 1977-88.

4 J. A. Walsh and K. S. Warren, "Selective Primary Health Care: An Interim Strategy For Disease Control in Developing Countries," Social Science and Medicine, 14C, 1980, pp. 145-163 (Proceedings of the Bellagio Conference).

5 Ibid., p. 145.

6 D. E. Bell, "Introduction," Social Science and Medicine, 14C, 1980, pp. 63-65. 
medium and low priority groups included diseases of "lesser importance or less amenable to containment." Four types of interventions, based on "reasonable cost" in controlling these diseases, were identified as part of a program to improve health in the developing world: 1) vaccination against infectious diseases, 2) oral rehydration, 3) maternal and child health programs including the promotion of breast feeding, and 4) supply of drugs for malaria. The action plan was only tentative, and countries may expand their primary health care, as they become economically developed to incorporate advanced technology and medical procedures. ${ }^{7}$

This was followed in 1985 by another conference titled "Good Health at Low Cost," which brought together a group of experts in epidemiology, demography and health economics to analyze four case studies namely China, Sri Lanka, Kerala State in India and Costa Rica, which were considered models of good health in spite of being low-income countries. It was argued that these populations have achieved good health at low cost simply by prioritizing their development goals to health, education and food security as fundamental objectives of their social and political organization. Thus, "after examining the results presented at the conference, the participants unanimously adopted the following recommendations: The four states which have achieved 'good health at low cost' have all clearly made a political and social commitment to...three additional factors, [which] appear to have played a major role in their success as measured principally by a marked decline in infant and child mortality rates, resulting in a commensurate increase in life expectancy approaching that of the developed world. These factors constitute recommendations for program-development in other countries: Equitable distribution and access to public health and health care; uniformly accessible educational system and; assurance of adequate nutrition at all levels of society." The conclusion of the conference was that if these four case studies were models of "Good Health at Low Cost," they provided the key to identify parameters, and to define strategies and the scope of similar models for other developing nations.

A strong case in favor of selective primary care can be made on the basis of Sri Lanka's primary health care system and its contribution to outstanding health indicators of that country.

The purpose of this paper is to examine the historical development of primary health care in Sri Lanka in the early twentieth century, and its contribution to overall health achievements during the past few dacades. The paper will argue that the community-based primary health care program, also known as the "health unit

7 Keneth S. Warren, "The Evolution of Selective Primary Health Care," Social Science and Medicine, Vol. 26, No. 9, 1988, pp. 891-898.

8 S. B. Halstead, J. A. Walsh and K. S. Warren, (eds.) Good Health at Low Cost: Proceedings of a Conference at the Bellagio Conference Centre, Italy, 29 April to 3 May 1985, Rockefeller Foundation, New York, 1985. 
system," was an earlier concept of selective primary health care developed by the International Health Board (IHB) ${ }^{9}$ of the Rockefeller Foundation and Sri Lankan public health experts. The first health unit established in 1926 at Kalutara, Sri Lanka served as a "model" of selective primary health care, which was gradually expanded across the country, and later introduced to other countries in South and Southeast Asia by the IHB in the early twentieth century. A key strategy of the health unit system was to identify the most common and serious infectious diseases in each health unit area and control them through improved sanitation, health education, immunization and treatment with the help of local communities. The health unit system was strengthened as part of the national health care program in the post-colonial period, and the first health unit established at Kalutara became Sri Lanka's National Institute of Health Sciences, which today is the country's premier training centre of public health personnel. Drawing from archival and secondary sources gathered at the Rockefeller Archive Center in New York, and the National Archives in Colombo, Sri Lanka this paper will discuss the key aspects of the health unit program and its contribution to the development of primary health care in Sri Lanka, which is considered one of best in the region. ${ }^{10}$

\section{Background: Rockefeller Philanthropy in Sri Lanka}

The Rockefeller philanthropic medicine arrived in Sri Lanka in 1916, when the hookworm infection was an epidemic among Indian immigrant workers on the plantations in Sri Lanka. The British plantation owners, who recruited South Indian labourers for their estates in Sri Lanka, were responsible for the welfare of their workers. The laissez-faire policy of the colonial government allowed the plantation owners to conduct their business according to their economic interests. As a result, planters ignored even the most basic requirements such as latrines in the living quarters of their workers. In the extremely poor sanitary conditions on the plantations, immigrant workers and their families faced the threat of numerous diseases, such as hookworm infection, typhoid, cholera and smallpox, which often became epidemics on the plantations. ${ }^{11}$ Despite the fact that a large number of the immigrant labourers arriving in Sri Lanka each year died of various diseases, the

9 The Rockefeller philanthropy in public health was first channelled through the Rockefeller Sanitary Commission created in 1909, which was renamed the International Health Board in 1916. In 1927, it was renamed again as the International Health Division. Throughout this paper, I will use IHB to represent Rockefeller philanthropic programs in public health in Sri Lanka.

10 Editorial, "Is there hope for South Asia? Yes, if we can replicate the models of Kerala and Sri Lanka," British Medical Journal, Vol. 328, April 2004, pp. 777-8.

11 S. V. Balasingham, The Administration of Sir Henry Ward, Governor of Ceylon, 1855-60, Tisara Prakasakayo, Dehiwala, Sri Lanka, 1968, pp. 51-55. 
planters were not bothered with the high death toll. According to K. M. de Silva, for example, in the years from 1841 to 1848 , about 70,000 (10,000 per year) or 25 percent of the immigrant workers died of various causes. The planters saw no dearth of cheap labour available in India. ${ }^{12}$

Following an agreement with the colonial government and the Plantation Owners' Association, the IHB began a mass treatment campaign for hookworm disease in the Matale district comprising 24 estates, with approximately 10,000 people. The representatives of the IHB, Drs J. E. Snodgrass, W. C. Sweet and W. P. Jacocks developed a working plan for Sri Lanka. The program was gradually extended to other estates. Besides the treatment of those infected, the campaign consisted of a study of suitable types of latrines for the estates, and an information campaign of the cause and prevention of hookworm disease. The information campaign included lantern lectures, distribution of pamphlets and demonstrations. In addition, they trained estate pharmacists to diagnose the infection using microscopic and clinical observations and to administer proper doses of chenopodium oil as treatment.

By the end of 1917, the hookworm control campaign had treated about 40,000 people. Of these, approximately 80 per cent were pronounced cured upon microscopic re-examination. In addition, morbidity statistics gathered from several estates showed a marked improvement in general health following the treatment for hookworm disease. The District Medical Officer of Matale reported that only 2,604 patients were admitted to hospitals in 1918, compared to 3,694 hospital admissions before the hookworm control program was begun, a reduction of 27 per cent. ${ }^{13}$

In spite of these improvements in the health of workers, they were not sufficient to convince the planters to undertake the major sanitary reforms recommended by the IHB. As the crucial requirement for the control of hookworm disease was the prevention of soil pollution, it was essential to construct adequate latrines. Although the planters had agreed at the beginning of the campaign to construct latrines, they did not honour their commitment. While the government introduced legislation making it compulsory for all the estates to provide sufficient latrines for their workers, it did not enforce the law. ${ }^{14}$ The unabated soil pollution on the plantations and the arrival of infected new workers from India ensured a high rate of re-infection. At the end of 1919, three years after the completion of treatment, an examination of a sample of about 3,000 workers showed that the infection had not declined.

12 S. Hewa, "The Hookworm Epidemic on the Plantations in Colonial Sri Lanka," Medical History, Vol. 38, No. 1, 1994, pp. 73-90.

13 Rockefeller Archive Center, (hereafter RAC), Relief and control of hookworm disease in Ceylon, 1918, pp. 27-37, Record Group (RG.) 5, Series (Se.) 2, Box 47.

14 Ibid., p. 8. 
The hookworm control campaign on the plantations could not achieve its goal because the sanitary conditions were not improved while the treatments were being carried out. ${ }^{15}$ At this point, it became clear to the IHB that neither the government nor the Planters' Association were seriously concerned about the hookworm problem. Although sharing the cost of the program, the government was not fully committed to the objective of improving sanitary conditions on the estates. It did not want to antagonize the powerful Planters' Association by forcing them to construct latrines, nor did it want to takeover the construction of latrines on the estates, as this might appear to be a change of the government's policy toward the plantations. The planters, for their part, believed that they could overcome the persistent complaints against them by letting the hookworm control campaign treat their labourers. However, anything that required capital spending was not something that they were prepared to undertake.

In April 1921, Dr Victor Heiser, the director of the IHB's operations in Asia, visited Sri Lanka and informed the IHB decision to stop its work on the plantations after 1922. He met with the government's officials, the Planters' Association and the medical personnel of the project to discuss the future of the campaign. The project director, Dr W. P. Jacocks, pointed out that given the state of sanitation, it would be futile to continue treatment activities on the plantations. ${ }^{16}$ After nearly six years of hookworm treatment program on the plantations and spending almost $\$ 200,000$ by 1922 , the IHB could neither reduce nor eradicate the hookworm infection on the plantations because sanitary conditions were not improved. Under these circumstances, Dr Jacocks advised that the IHB should shift its hookworm control campaign to selected villages and towns on the rest of the island. For an initial program, he recommended the Western province given its relatively better infrastructure facilities at that time. He also proposed that in addition to carrying out treatment for hookworm infection in villages and towns, a survey should be taken to determine the prevalence of major health problems and their underlying causes across the island.

Although the hookworm control campaign on the plantation failed to achieve its intended goal, it provided a window of opportunity for the IHB representatives in Sri Lanka to gain first-hand knowledge about the socio-economic condition vis-àvis health across the country under colonial rule. It also gave them an opportunity to reflect more closely on the importance of sanitation and public health in preventing disease. Unlike on the plantations, the hookworm campaign in the towns and villages in the Western province received better response from both the

15 RAC, Relief and control of hookworm disease in Ceylon, pp. 18-20, 1920, RG. 5, Se. 2, Box 47.

16 RAC, European Planting Community in Regard to Medical Aid and Sanitation, p. 1, 1921. RG. 5, Se. 2, Box 47. 
people and the government officials. ${ }^{17}$ In particular, there was a considerable interest in public health work among people, who cooperated with the hookworm program while voicing their criticisms of its limited scope in view of their wideranging health problems. Life outside the plantation was relatively free from repressive and callous exploitation underwent by the immigrant labourers. People were able to question or criticize the hookworm campaign without being subjected to punishment or dismissal from employment, as was the case on the plantations. ${ }^{18}$ The hookworm campaign provided people an opportunity to express their grievances regarding the lack of public services in their communities. They demanded attention to their more urgent health problems, and questioned the rationale of giving treatment for hookworm infection when there were numerous other diseases such as typhoid, smallpox, dysentery, malaria etc., which were more serious and debilitating. ${ }^{19}$ In the end, the Rockefeller doctors themselves became critical of their own work. The juxtaposition of Western medicine and the pragmatic response of the villagers changed the main thrust of Rockefeller philanthropic medicine in Sri Lanka. A decade of public health activities in Sri Lanka convinced the Rockefeller doctors that no effective public health program could be developed overnight and that a carefully planned system must be established through demonstration and education over a long period. More importantly, for the success of such a program the active involvement of the local communities and leadership must be a vital component. ${ }^{20}$ For the program to be effective, the IHB officials discovered, it had to recognize as legitimate the needs and living experiences of the villagers. That is, these villagers had to be "heard" their understanding, consent and participation were required.

17 For a detailed discussion, see Soma Hewa, Colonialism, Tropical Disease and Imperial Medicine: Rockefeller Philanthropy in Sri Lanka, University Press of America, Lanham, MD, 1995.

18 Sri Lanka National Archives (hereafter SLNA), Despatch No.6, April 21, 1847, 5/34. Even if the workers understood their rights, they could do absolutely nothing against the planters. Commenting on the helpless situation of the workers, a pioneer coffee planter observed the following: "What redress could the poor coolies, for instance, have against his European master who ill-treated him, miles away in the jungle, far from a magistrate or a court, with all his fellows up in arms against him, lest they should lose their employment, and his wife and family almost at the complete mercy of his persecutor, or of that persecutor's assistants?" W. Knighton, Forest Life in Ceylon, London, 1854, p. 124.

19 It should be noted that the development of clinical symptoms of hookworm disease is a long process, a fact that influenced the public reaction to the treatment campaign. The disease does not make someone sick suddenly; it gradually weakens the infected person as the intensity of the disease increases, making the person vulnerable to other virulent infections. Consequently, most villagers were puzzled by the vigorous campaign of hookworm control when they were not even aware of any sign of the disease. RAC, Summary Report, Anchylostomiasis CampaignsCeylon, p. 12, 1921. RG. 5, Se. 3, Box 193.

20 RAC, Preliminary Report on Health Units, p. 3, 1926. RG. 5, Se. 2, Box 48. 
An equally important development was the government's about-face, following decades of indifference to issues related to the health needs of those beyond the urban centres. The government was itself responding to a variety of conditions, including growing concern for public health in the Western world generally, and the increasing agitation of Sri Lankan intellectuals - part of a growing middle class - who were making known the need for education and health in the countryside. The government's reorientation toward public health in the country created space for the IHB to play an active role without being perceived as interfering with the government's affairs. An understanding was reached between the IHB and the government that a program must be developed to address basic sanitary services, vaccination for communicable disease, the maternal and childcare, and public health education and training in the country. If successful results could be achieved in developing an effective program in one district, it should be used as a model for others. A public health campaign of such magnitude would inevitably take time. ${ }^{21}$ The IHB, together with local health officials, developed a complex plan that was embedded into the governmental administrative mechanism, which they directed for many years. Positions were added to the existing administrative apparatus, and their mandates were extended and animated to carry out new duties related to public health. This program became the framework and impetus for the remarkable achievements in public health in Sri Lanka. ${ }^{22}$

\section{Conceptual Framework of the Health Unit Program}

Although the IHB had experimented with the health unit concept in the southern United States, it did not implement the same program in Sri Lanka. Instead, while recognizing the universality of public health principles, the authors of the Sri Lanka's health unit program focused on the specific health problems in Sri Lanka. Although the general objective of the health unit program was "to meet the health needs of populations living in rural and semi-rural areas," the core principles of the program were disease prevention and health education: "It is based on standard public health organizations in which all recognized health activities are carried out. In addition to its routine work, the unit may be regarded as an area for testing methods of procedure - that is, a field laboratory - for application elsewhere." ${ }^{23}$

It was argued that every community across the country experienced more or less the same health problems, the root causes of which were the poor sanitary conditions and the inadequate public health services. In this context, when

21 Ibid., pp. 3-5.

22 Ibid., p. 8.

23 S. F. Chellappah and W. P. Jacocks, 1936, Guide to Health Unit Program, Preface to the first edition, Colombo, p. 1 
"undertaking general public health measures," argued Dr Jacocks, "it is considered advisable by those most experienced to begin work on a small scale in a restricted area. A lively campaign against all preventable diseases should not be immediately undertaken. Even were this possible, it would be unwise, for the method of attack may vary in different countries. The preventable diseases peculiar to the district should be determined by a careful survey and they should be thoroughly studied and attacked in the order of their importance as a cause of morbidity and mortality. The work should then be gradually enlarged to include all the public health problems in the area." ${ }^{24}$ We may recall that the key strategy of the selective primary health care was to attack health problems on the priority basis - from the most serious infectious diseases causing the greatest number of preventable illness and death to the least preventable disease by the existing methods.

The required personnel to carry out the health unit work clearly suggested the nature of the health unit work. Three major categories of well-trained public health personnel were identified as a permanent staff to carry out the activities of each health unit. For a population of 40,000, the following numbers of health workers were recommended: one medical officer of health, five public health nurses, five sanitary inspectors, and ten midwives. Besides these health care professionals, two office workers and a labourer were required for record keeping and the maintenance purposes. The health care professionals were expected to work as a team and, in particular, the last three groups would assist each other in their field operations. The responsibilities of the each person were clearly spelled out in the program:

1) Medical officer of health, ${ }^{25}$ who was to serve as the director of the health unit, expected to coordinate all activities to ensure that "public health inspectors, nurses, and midwives carry out the work as planned. This is accomplished by making frequent visits to each member of the field staff in every part of the area." ${ }^{\text {,i26 }}$ The medical officer must investigate health problems in the area, make regular visits to schools, conduct clinics for vaccinations, maternity and child welfare services and provide health education through public lectures and propaganda. It was clearly state that the health units do not provide curative services, except when conducting hookworm and malaria control campaigns. The health units must refer patients to the local hospital or dispensaries for curative services. Further, the medical officer was also responsible for bringing social and economic problems of the community that had health implications to the attention of local authorities and respective

24 RAC, W. P. Jacocks, Preliminary Report on Health Units, pp. 4-11, 1926, RG. 462, Se. 2, Box 48.

25 In the event that a health unit had to recruit more than one medical officer, they would be assistants to the senior medical officer.

26 S. F. Chellappah and W. P. Jacocks, 1936 A Guide to Health Unit Procedure, Colombo, p. 7. 
government departments for action. In collaboration with other government departments, the medical officer must develop supplementary nutritional programs for expectant and nursing mothers and infants. Regular surveys must be conducted to determine the nutritional requirements and to evaluate the progress of on-going activities. As a part of the health education campaigns, the medical officer must develop a nutritional guide advising on how to prepare affordable and healthy daily meals using the available fruits and vegetables grown in most villages. ${ }^{27}$

2) Public health nurses must have an additional training in maternal and childcare, administration of treatment for hookworm and malaria. They must reside in the health unit area and regularly visit communities to discuss health issues, visit schools and local dispensaries to obtain a good sense of prevailing health problems. It was argued that the nurses who would be most effective were "strong in character, sympathetic but forceful, and possessed of commonsense, tact and initiative."

3) Sanitary inspectors must be fully dedicated to sanitary work and be given additional training in malaria control work and the mass administration of hookworm treatment. It was argued that sanitary inspectors must "become well known in the...assigned area and gain the cooperation of the people." They must undertake experiments to determine the appropriate type of latrines and wells for specific terrains in the health unit area, and carry out regular inspections regarding the sanitary condition. They must coordinate all sanitary work with the local authorities, and assist "nurses and midwives whenever practicable." Sanitary inspectors must also organize local voluntary groups to assist their work.

4) Midwives were placed under the immediate supervision of the public health nurses, and each midwife was expected to serve about 4000 people within a radius of three miles. They must live in the area where they work. The midwives were responsible for locating expectant mothers, arranging early medical examinations and attending the birth if the pregnancy was normal. Following the birth, they were required to visit the mother and newborn daily for ten days. In case of medical complications during pregnancy, the midwife must ensure that a doctor was called or that the mother was taken to the hospital. They must follow a standard set of guidelines developed by the medical officer regarding prenatal to postnatal care to ensure the health of both mother and child. ${ }^{28}$

Once the personnel for the health unit were recruited, the next step was to conduct a series of public lectures using lanterns on various aspects of sanitation and disease control to induce interest among the public. "The cooperation of the people is so important that it is given every emphasis... To get lasting results the work must be placed on a cooperative basis which is the foundation of the Health

27 Ibid., pp. 37-38.

28 Ibid., pp. 6-8. 
Unit system. The organization of the people for cooperative assistance is so important that the officer in charge of the Health Unit should consider his plan of work to be unsatisfactory until this is done."29 [Original emphasis] It was recommended that the community involvement must be sought in all aspects of the health unit work, and to this end, the most important task was to develop as many voluntary organizations as possible with the help of the local community leaders. The community organizations were seen as a critical tool in assisting the health unit to carry out mass vaccinations, hookworm treatment and major sanitary work in the area. Moreover, it was pointed out that community leaders as opinion makers could play a powerful role in public health education and propaganda work in the community.

The next most important step of the health unit work was to undertake a survey of the health unit area to answer the following critical questions: 1) what was general sanitary situation in the health unit area, 2) what were prevailing major diseases, morbidity and mortality rates, and the affected communities, 3) what was the general public attitude toward the work. Based on the findings, the medical officer should be able to distinguish between the overall health situation, specific health problems and major health problems in the health unit area. It was argued that this information was the key to the future work of the health unit. Following the careful review of the findings, the outstanding health problems were to be "attacked in the order of their importance as a cause of morbidity and mortality" in the area.

\section{Implementation of the Health Unit Program}

A "health unit" referred to a geographical area comprising up to 80,000 to 100,000 inhabitants. According to the program, the island would be divided into approximately 63 health units. It was estimated that an average population of a health unit would be about 83,000 people. The first health unit in Asia was established in 1926 at Kalutara-Totamune, ${ }^{30}$ a suburb $43 \mathrm{~km}$. south of Colombo. The suitability of Sri Lanka to experiment with the health unit concept was clearly stated in various preliminary reports. "In Ceylon active interest is being manifested

29 Ibid., p. 3.

30 The area that the health unit was initially expected to serve was about 25 square miles with a population of approximately 30,000. The area included 1 urban centre, 27 villages and 7 large rubber plantations. The selected area provided a balanced representation of the island's population and their health problems at the time. Given the importance of the first health unit, Dr S. F. Chellappah, who was one of the authors of the health unit program in Sri Lanka, became the senior medical officer of the Kalutara health unit. Dr W. P. Jacocks of the International Health Board opened the health unit on July 1st, 1926. RAC, First Annual Report of the Health Unit Kalutara Badda, p. 1, 1926. RG. 5, Se. 3, Box 198. 
in public health in both official and non-official circles," argued Dr Jacocks. Perhaps the most important reasons were the geographical location of the island and its relatively better infrastructure with a small population, which were regarded as ideal for a field experiment on a public health program: "Ceylon lends itself well for the establishment of such organization," argued Dr Jacocks. In addition, the existing administrative system of the country provided an established "framework" for the health unit system that could function alongside the local government. Thus, the relationship between the local administration and the health unit was one of close cooperation and shared responsibilities. ${ }^{31}$ The Government Agent and the Assistant Government Agents of the province provided administrative assistance to the medical officer of health in charge of the unit. The local government authority (the Municipal Council/Urban Council) was expected to transfer its health and sanitary work and personnel to the health unit. In addition, the local government was responsible for enacting necessary sanitary regulations to facilitate the activities of the health unit. The local authority in return benefit from the services of a fulltime medical officer of health, of public health nurses, and of all the facilities established in the area by the Department of Medical and Sanitary Services. ${ }^{32}$

During the opening ceremony of the first health unit, Dr Jacocks stated that "[this day] will be remembered by health workers in Ceylon as the day on which a real step forward was taken in rural health work along modern lines. Health work up to now in Ceylon has dealt, largely, with the environment, but in this new development the hygiene of the individual is receiving attention in addition." 33 The first health unit was considered important because it would be used as the model for future programs in other areas of the country: "It was intended to determine, by the experience gained in this unit, standards of work, of procedure, of personnel etc., suitable for local conditions; and also to stimulate interest among the public in this type of health work. Further, this unit was also to be a training centre for personnel to be employed in future health work." 34 As seen in Figure 1, the organizational structure of the health unit system became quite complex. A new post of Superintendent of Health was created within the Ministry of Health to promote health education and information throughout the country. As health education was the key to successful promotion of public health, the position was filled by an experienced Sri Lankan, who was given a post-graduate fellowship by the IHB to obtain further training in public health education in the United States.

31 RAC, Preliminary Report on Health Units, pp. 4-5, 1926. RG 462. Se. 2, Box 468.

32 RAC, The First Annual Report of the Health Unit Matara, pp. 2-8, 1928. RG. 5, Se. 3, Box 201.

33 RAC, First Annual Report of the Health Unit Kalutara Badda, p. 1, 1926. RG. 5, Se. 3, Box 198.

34 Ibid., p. 1. 
FIGURE 1

Organizational Structure of Health Units

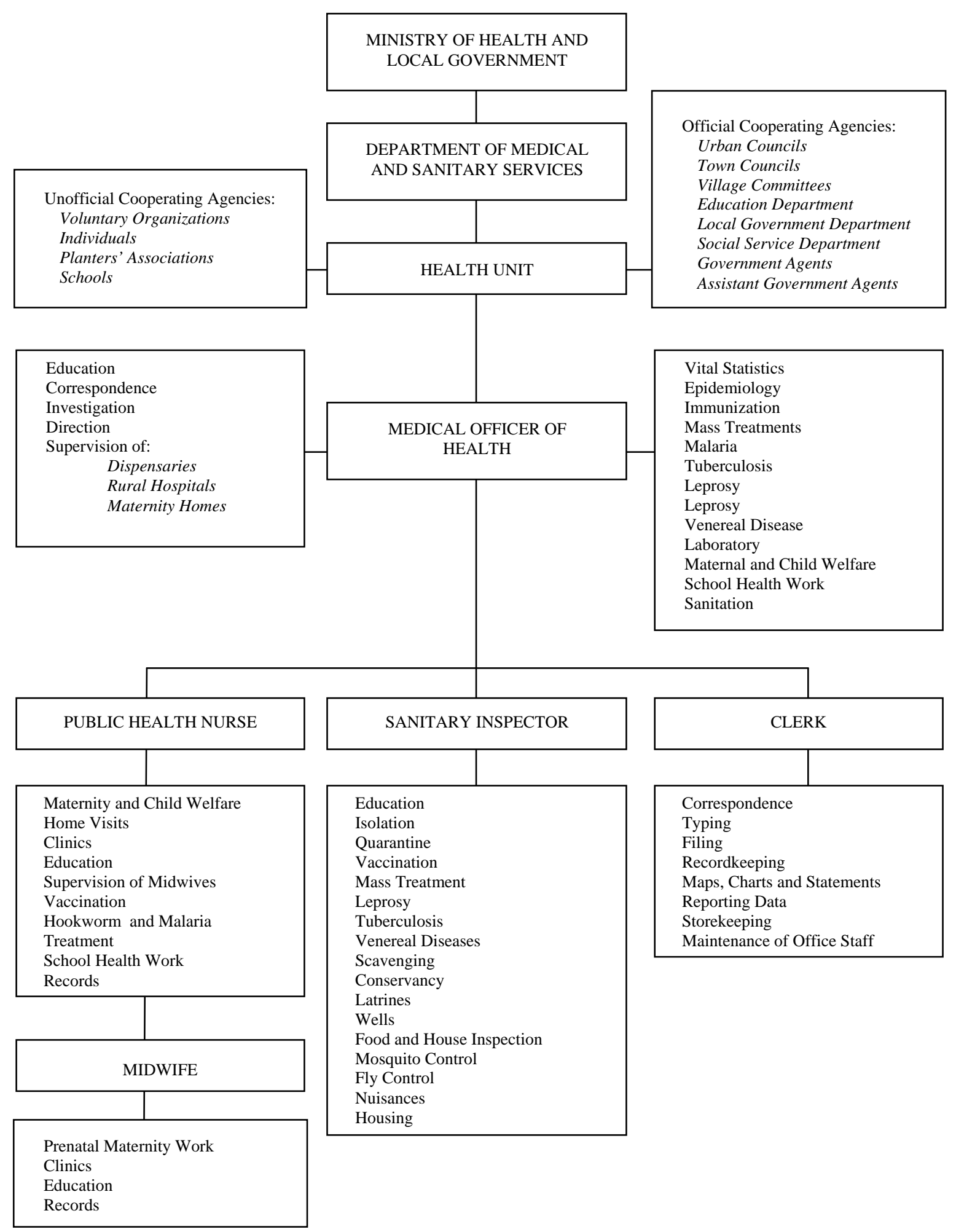

Source: S. F. Chellappah and W. P. Jacocks, A Guide to Health Unit Procedure, Colombo, 1936, P. 50. 
The health survey of the Kalutara health unit area identified eight infectious diseases as major causes of death among all ages: 1) dysentery, 2) typhoid, 3) hookworm infection, 4) measles, 5) tuberculosis, 6) influenza, 7) smallpox, and 8) whooping cough. In addition, among infants below one year, three major causes of death were identified: 1) convulsion, 2) premature birth, and 3) infantile debility. More than half the deaths occurred during the first three months.

\section{Measures to Control Disease: Education, Sanitation, Immunization and Treatment}

Following the health survey, several measures were taken to control disease. In view of a limited number of trained public health workers available to carry out an extensive program, the tasks were organized as "seasons." In one season, for example, health education on disease prevention, followed by latrine construction and water supply programs, vaccination against smallpox, and so on. It was believed that this method would enable every individual employed by the health unit to concentrate on one particular task without interruption from beginning to end. ${ }^{35} \mathrm{~A}$ series of lectures were delivered at market places and schools to educate the public. A number of health exhibitions were held at Kalutara town to encourage mothers for breastfeeding. These exhibitions were part of the regular "Health and Baby Weeks" program, which provided information on postnatal care for young mothers. Saturday conferences with the health unit staff were regular features of the health unit. These conferences were attended by the officials of the local administration, Ayurvedic doctors (native physicians), teachers, parents and many local dignitaries. It was argued that these conferences proved very effective in providing basic health education for the local residents, whose cooperation in sanitary reforms was essential. The locally appointed public health nurses, midwives and sanitary inspectors played a key role in organizing these activities. Their services were especially mentioned in almost every annual report. ${ }^{36}$ The Kalutara health unit was awarded the "Empire Challenge Shield" for 1929 by the National Baby Week Council of England for organizing the best Baby Week held in the British Empire excluding the British Isles.

By the end of 1929, there were five health units across the country serving approximately 225,000 people, about five percent of the total population of the country. Of these, about 18 percent were living in urban areas. The priority of public health needs was established based on health surveys and the vital statistics

35 Ibid., p. 12.

36 RAC, Annual Report on Health Unit Work, pp. 6-8, 1928. RG. 5, Se. 3, Box 199.

37 RAC, Division of Sanitary Engineering, Ceylon, Report on Ceylon for 1929, p. 4, 1930, RG. 5, Se. 2, Box 47. 
gathered by the health units. The infant mortality rates varied from the lowest in the Western province to the highest in the Northwestern province. Of all the five provinces where health units had been established, the Northwestern province had the lowest birth rate (28.2 per 1000), the highest death rate (31.1), the highest infant mortality rate (248.0) and the highest maternal mortality rate (28.6). The report attributed the higher death rates in the Northwestern province to malaria, which was endemic in the region. ${ }^{38}$ Even with the relatively better sanitary conditions in the Kalutara health unit, 46 percent of all deaths among children occurred before the fifth year of life. In the Northwestern province, infantile debility was the main cause of death with pneumonia a close second (198 and 195 per thousand live births respectively) during the first year of life. ${ }^{39}$ In 1929, the Kalutara health unit reported the highest incidence of typhoid, chicken pox, dysentery and measles. In addition, all the health units reported the cases of hookworm infection.

In light of these vital statistics from the health unit areas, steps were taken to improve sanitary conditions during the late 1920s. The large-scale sanitary projects were begun in all health unit areas with the inauguration of a sanitary engineering division $^{40}$ of the Department of Medical and Sanitary Services in 1927. This particular division spearheaded the campaign to improve public health. The construction of hundreds of private and public latrines, and community wells for drinking water in each health unit area was regarded as one of the most important steps toward the development of public health in the country. In 1929, for example, in the Weudawili Hatpattu (Northwestern province) health unit 421 private latrines were built by the health unit in collaboration with the local government. Other health units, such as Matara (Southern province), Paranakuru Korale (Sabaragamuwa province) and Kalutara also constructed over one thousand private and public latrines during the period. ${ }^{41}$ In addition to these new latrines, hundreds of existing ones were restored according to the specifications of the newly created sanitary engineering division. Further, a major water supply scheme was undertaken for the Kurunegala health unit are in the Northwestern province, and a similar project had already been completed at Kalutara. A preliminary investigation had also been done of the water supply for the Trincomalee health unit in the Eastern province. The construction of latrines and water supplies were considered the

38 RAC, Annual Report on the Health Unit Work, p. 33, 1929. RG. 5, Se. 3, Box 200. For a discussion on the impact of malaria and hookworm on pregnancy, see G. A. W. Wickramasuriya, Malaria and Ankylostomiasis in the Pregnant Women, London, 1936.

39 RAC, Annual Report: Weudawili Hatpattu, pp. 16-17, 1930. RG. 5, Se. 3, Box 200.

40 The establishment of a sanitary engineering division, under the leadership H. N. Worth, was a brainchild of W. P. Jacocks, the IHB representative in Sri Lanka. RA, Anchylostomiasis Campaigns, Ceylon, A Letter to V. Heiser from W. P. Jacocks, November 28, 1927, RG 1.1, Se 3, Box 1.

41 RAC, Annual Report on Health Unit Work, p. 30, 1929. RG. 5, Se. 3, Box 198. 
priority of all health units. In most of the rural areas across the country, the water supply was mainly through wells. The sanitary inspectors regularly examined the conditions of these wells. Further, to improve the sanitary conditions in the towns and villages, specific regulations were enacted in 1926 regarding the operation of restaurants, bakeries, butcher shops, fish and vegetable markets, dairy farms and laundries. All trade premises were regularly inspected by sanitary inspectors to insure that the owners complied with regulations. A whole range of sanitary reforms had already been completed or was underway in a number of provinces following the opening of the first health unit. These various sanitary activities clearly showed a serious commitment to deal with basic sanitary problems throughout the country. ${ }^{42}$

Sanitary works were followed by a mass immunization campaign for typhoid and smallpox in all health unit areas. The recurring epidemics of typhoid and smallpox killed thousands of people in many parts of the island. Referring to the successful control of smallpox, C. G. Uragoda, a Sri Lankan medical historian, maintains that the "extensive vaccination, helped by legislation, was largely responsible for this happy situation. Whenever cases of smallpox occurred, energetic vaccination in the area was carried out, thereby preventing further spread." ${ }^{\prime 3}$ A total of 6128 people were vaccinated against smallpox in $1930 .{ }^{44}$ The immunization program at the beginning relied heavily on private donations and charities. The campaign was largely concentrated in the Kalutara health unit area due to the financial assistance received from private individuals in the province. It should be noted that a large number of Europeans and mixed descendants (Burghers) were living in the Western province. Further, it can be suggested that the concentration of a fairly large European population in the province may have attracted the attention of the government as well.

One of the most important activities of the health units was the "child welfare" works, which were organized by the public health nurses of the health units in collaboration with the local schools. ${ }^{45}$ The public health nurses visited schools in the province to conduct clinics on sanitary matters. Further, they made regular home visits to advise mothers on childcare. Those in need of these services often outnumbered the available nursing personnel in each health unit, demonstrating that the child welfare work were the most demanding of all activities of the health

42 Ibid., pp. 29-30.

43 C. G. Uragoda, A History of Medicine in Sri Lanka-from the earliest time to 1948. Sri Lanka Medical Association, Colombo, 1987, p. 213.

44 RAC, Ceylon Health Units, A Summary of Health Unit Information for the Year 1930, pp. 14, 1931, RG. 1.1, Se. 462, Box 1.

45 Commenting on the declined infant mortality rate from 235 in 1924 to 216 per 1000 live births in 1927 on the island, Dr J. F. E. Bridger, PCMO, attributed the trend to the activities of child welfare associations. British Medical Journal, Vol. 1, 1927, p. 538. 
units. As a result, a special program of recruiting and training public health nurses and midwives was introduced by the Department of Medical and Sanitary Services in the latter part of 1929. The response of the people with regard to child welfare work was more positive than to any other service provided in most health unit areas. Particularly in the Northern and Eastern provinces, where there was a chronic shortage of doctors, the only public health workers available in most communities were the midwife and the sanitary inspector. Therefore, people "well understood the benefit of having a trained midwife or a sanitary inspector in the community." Because of the growing demand for maternity and child welfare services across country, the number of rural dispensaries increased almost by fivefold during the 1930 s

In addition to immunizations, mass hookworm treatment campaigns were carried out in Southern, Western and Northwestern provinces. In 1930, seven health units across the country treated more than 9000 people for hookworm infection. A central laboratory in Colombo examined faecal specimens, blood, urine, sputum, and water samples collected from different provinces. Although the central laboratory for the examination of various samples collected from all over the country was useful at the beginning, it could not meet the increased demand for such services as the number of health units increased. The long delay of analyzing samples often prevented the medical officer of health from taking urgent action to control disease. The advantage of having a laboratory in a province itself was demonstrated when the medical officer of health in the Matara health unit (Southern province) was able to take immediate action to deal with an outbreak of pneumonic plague during year before the local findings were confirmed by the central laboratory in Colombo. As a result, it was recommended that at least one medical laboratory should be established in each province, providing that the central laboratory in Colombo would continue to handle the major examinations. ${ }^{47}$

\section{Malaria Control Work}

Despite significant improvements in public health on the island, particularly in the health unit areas, recurring malaria epidemics became a serious health problem in the country. ${ }^{48}$ The great malaria epidemic in $1934-35$ was preceded by a major drought when the annual rainfall fell considerably below the normal throughout the country. As a result, the water levels of the major rivers, lakes and reservoirs

46 RAC, The Report on the Work of the Trincomalee Health Unit, pp. 38-9, 1930, RG. 5, Se. 3, Box 201.

47 Ibid.

48 B. L. C. Johnson, South Asia, Selective Studies of the Essential Geography of India, Pakistan and Ceylon, Barnes and Noble, New York, 1971, pp. 143-4. 
declined providing ideal breeding places for anopheles. The epidemic began in the Northwestern province and gradually spread into Western and Southern provinces. At the height of the epidemic, almost the entire population, or more than five million people, were affected by the disease. ${ }^{49}$ The epidemic has been described as the "greatest pestilence in the recorded history of the Island, and a catastrophe of the first magnitude." ${ }^{\prime 0}$ By the end of 1934, the attendance at the government hospitals and treatment centres had reached more than 60,000 patients a day. By the end of 1935, the epidemic had killed more than 80,000 people.

Although sporadic malaria control campaigns had been conducted by various government departments and the local authorities since the late nineteenth century, ${ }^{52}$ they had very little effect in controlling the disease. The outbreaks of malaria occurred quite regularly. As a result, the anti-malaria measures were later incorporated with the activities of the sanitary department. The first organized effort to control malaria was begun in 1921 although much of the work was rudimentary in nature. The anti-larval measures such as oiling, application of Paris Green (an early type of insecticide), and minor drainage programs were mainly confined to major urban centres. In most rural areas, there were no regular malaria control measures. ${ }^{53}$ As early as 1925 , the IHB sponsored two medical experts on malaria - Drs M. E. Barnes and Paul F. Russell 015 - to carry out a survey on the intensity of the malaria problem, and the appropriate measures to control it. They pointed out that malaria was "endemic and occasionally epidemic in Ceylon, and that the disease constitutes a public health problem of sufficient importance to merit special attention." ${ }^{54}$ In light of the frequent outbreaks of malaria throughout the country, Barnes and Russell recommended a more comprehensive program for the whole island instead of the scattered effort to control the disease. As they put it, "from the point of view of control, malaria is a local problem. Any plan for effective control should begin on a small scale in a few limited centres, and should gradually extend throughout the island." 55

49 Editorial, "Reports of Societies, The Malaria Epidemic in Ceylon," British Medical Journal, 1935, pp. 1015-7.

50 SLNA, Report on the Malaria Epidemic in Ceylon in 1934-35, Sessional Paper 23, Colombo, 1935, p. 5.

51 For an important analysis on the impact of malaria, see Wickramasuriya, op.cit., pp. 5-33. This study provides an excellent first-hand scientific data on this subject as it was done during the malaria epidemic between 1934-5.

52 For a brief history, see Uragoda, op.cit., pp. 217-31.

53 RAC, Malaria Eradication in Ceylon, p. 6, 1948. RG. 5, Se. 2, Box 47.

54 RAC, A Program for the Control of Malaria in Ceylon, M. E. Barnes and Paul F. Russell, Colombo, p. 3, 1925, RG 5, Se. 2, Box 48. Deaths from malaria were 5.8 percent of all recorded deaths on the island between 1936 and 1946. See E. J. Pampana, "Effects of Malaria Control on Birth and Death Rates," in Proceedings of the World Population Conference, United Nations, New York, 1954, p. 504.

55 Ibid., p. 9. 
However, the government did not implement these recommendations due to financial difficulties. After the devastating malaria epidemic in 1934-35, the government began taking some measures to deal with the problem. It started using pyrethrum as an insecticide for destroying adult mosquitoes in major endemic areas. The program lasted only a few months because of the outbreak of World War II. The government maintained that it could not afford to spend Rs. 12,000 15,000 (about \$ 5,000) annually for malaria control given the depressed financial situation of the country. By 1945, malaria had become the leading cause of death in the country. ${ }^{56}$

The turning point of the battle against malaria was the development of DDT during the war. ${ }^{57}$ In September 1945, several malaria observation stations carried out experiments with DDT in a number of districts in the North-Central province. The results showed a remarkable decline in malaria incidence within six months. A program of residential spraying of DDT was established in malaria endemic regions. The spraying was carried out on a regular basis (once every six weeks). The program was under the administrative control of the medical officer of health of the district. The IHB representatives provided technical advice in malaria control in those areas where the health units had been established. By this time, there was at least one health unit per province, with many in operation in the Western province. The health units carried out a number of malaria control programs, such as antimalaria drainage, oiling and the residential spraying of DDT. The medical and sanitary engineers employed by the health units were temporarily assigned to carry out malaria control work in those areas where the problem was acute. Moreover, in all questions concerned with malaria control within the health unit areas, the medical officer in charge assisted in collecting the essential field data, designing the schemes and presenting the detailed plans to the Department of Sanitary Services or to the local authority.

An intensive three-year-program of residential spraying of DDT brought malaria under control. ${ }^{58}$ By 1948, the malaria morbidity rate had declined to 109 per

56 RAC, Malaria Eradication in Ceylon, p. 7, 1948, RG. 5, Se. 2, Box 47. Also see Margaret Jones, "The Ceylon Malaria Epidemic of 1934-35, A Case Study in Colonial Medicine," Social History of Medicine, Vol. 13, No. 1, 2000, pp. 87-109.

57 For a discussion on the role of Rockefeller philanthropy in the development antimalaria technology, see D. H. Stapleton, "Technology and Malaria Control, 1930-1960: the career of Rockefeller Foundation engineer Frederick W. Knipe," Parassitologia, Vol. 42, No. 1-2, 2000, pp. 59-68; also by the same author, "Historical Perspectives on Malaria: The Rockefeller Anti-malaria Strategy in the 20th Century," Mount Sinai Journal of Medicine, Vol. 76, 2009, pp. 468-73.

58 Ibid., p. 12. 
thousand..$^{59}$ As one observer noted: "At a reported cost of two dollars per capita, the people of Ceylon acquired a modern life expectancy. A great deal of land previously in the possession of malaria mosquitoes was opened up for cultivation." ${ }^{60}$ In comparison with the programs conducted elsewhere, the approach taken by the health units to control malaria in Sri Lanka was cited as an example for others to follow. ${ }^{61}$ The effective malaria control campaign developed by the health units in the 1940's in accordance with the unique ecological conditions in the island turned out to be remarkably cost effective. The decline of malaria incidence after the late 1940 s directly contributed to the dramatic fall of mortality rate in the country. ${ }^{62}$ Sri Lanka, once among Asia's worst affected nations for malaria, is now close to eliminating it. ${ }^{63}$

\section{Community Support for Health Units}

One of the core principles of the health unit concept was to build a strong community support for the health unit work, so that the community would be responsible for providing resources and leadership and, above all, carrying out the activities assigned to citizens by public health officials. Such cooperation would ensure the sustainability of the program. In a report titled, $A$ Guide to Health Unit Procedure, the authors of the health unit program, Drs Jacocks and his Sri Lankan counterpart S. F. Chellappah described the importance of community involvement as follows: "To get lasting results the work must be placed on a co-operative basis which is the foundation of the Health Unit system. Co-operation is obtained by carefully explaining...the objectives to be attained and assistance which those concerned may give in helping to carry out the program.." ${ }^{.64}$ Clearly, the Health Unit program was designed to draw a collective response to local health needs and to utilize local resources, both material and human. In 1933, writing to IHB's New York office on continuing progress of the health unit program, Dr Jacocks specifically mentioned that the health unit work was receiving "considerable

59 The spleen rate had fallen from 30.6 in March 1936, and 21.2 in March 1938, to 5.18 in March 1948, and 3.5 in September 1948. RAC, Malaria Eradication in Ceylon, p. 31, 1948. RG. 5, Se. 2, Box 27.

60 G. Williams, The Plague Killers, Charles Scribner, New York, 1969, p. 180.

61 G. Harrison, Mosquitoes, Malaria and Man: A History of Hostilities since 1880, E. P. Dutton, New York, 1978, p. 255.

62 DDT was used until 1977 when it was replaced with Malathion. See Uragoda, op.cit, p. 229.

63 IRIN, Sri Lanka: on track to eliminate malaria, UN office for the coordination of humanitarian affairs, 2008.

64 Chellappah and Jacocks, op. cit., p. 3. 
assistance" from the people: "In fact the work is popular and its popularity is steadily increasing."

The three levels of co-operation - individual citizens, community organizations and local authorities - were sought and received by health units. Ten years after the first health unit was established, the authors of the program expressed immense satisfaction with the support it had received at various levels. At the individual level, local philanthropists built dispensaries for health units, and others furnished buildings for holding weekly maternity clinics, donated lands, pumps for wells, and a few have offered "Challenge Shields" to stimulate health education among school children. ${ }^{66}$ With the growing demand for maternity and child welfare services, the health units relied heavily on the assistance of community organizations such as Social Service Leagues, Child Welfare Leagues and Health Leagues. Health units launched a campaign to promote community health volunteers. In 1931, there were 24 such voluntary organizations working with health units. During that year, these voluntary organizations had contributed Rs. 16,802 (about \$ 6000) to health units across the country. ${ }^{67}$ The Trincomalee Health League was formed by a group of women who took special interest in child welfare work in the town. The League established three child welfare centres and carried out regular "Health and Baby Week" programs devoted exclusively to help vaccinate children. Many of the Health Leagues across the country were also involved in promoting family planning and breastfeeding among young mothers. Further, the Social Services Leagues played a key role in constructing latrines and wells in many parts of the island. ${ }^{68}$ In addition, Social Services Leagues provided free sewing lessons for young mothers. These voluntary organizations were "supported by donations, monthly contributions and special collections, and their activities [were] not a charge against the Health Unit budget." ${ }^{\text {"99 }}$ The health volunteer program became very popular among educated women during the post-colonial period. The local authorities, such as municipal and urban councils, welcomed the program as it enabled them to incorporate their regular health and sanitary work with the health units without having to bear additional financial burdens.

65 RAC, Kalutara Health Unit, Ceylon, A memo from W. P. Jacocks to V. Heiser, May 3, pp. 1-2, 1933, RG. 1.1, Se. 462, Box 1.

66 RAC, Annual Report: Health Unit Work, pp. 5, 9, 12, 13, 15, 1928, RG. 5, Se. 3, Box 199. Local philanthropists built several dispensaries for health units across the country. For example, the dispensaries at Dondra and Walgama in the Matara health unit were built by Mr. Pabiris Silva, Mr. Weeratunga, and Mr. Wickremesinghe. RAC, The Annual Report, Health Unit Matara, p. 47, 1930. RG. 5, Se. 3, Box 201.

67 RAC, 1932 Maternity and Child Welfare, Annexure (M), p. 3. RG. 462.

68 M. Perera, Sri Lanka Study of Health Volunteers, International Review of Community Health Workers-Policy and Practice, Marga Institute, Colombo, 1987, p. 24.

69 Chellappah and Jacocks, op. cit., p. 3. 


\section{Conclusion}

In the preceding sections, we examined the development of the community-based health unit program, which was the origin of the concept of selective primary health care. It was developed by the IHB in collaboration with the Sri Lankan public health experts long before the WHO began to discuss primary health care for developing countries. Unlike the comprehensive primary health care of the Alma-Ata Declaration, which recommended broad social and economic reforms to promote health, the health unit program restricted itself to most serious health problems in the community and attacked their root causes in the order of their importance for the health of the people by using available techniques and the local resources. The health unit system was developed in view of local conditions, resources and administrative mechanisms in partnership with the local people. In the process, people became stakeholders of the health unit system. As a result, it was practical and inexpensive. As Uragoda has noted, the health unit work in Sri Lanka differed markedly from other primary health care programs sponsored by the WHO in developing countries, where primary health care combined both curative and preventive medicine. In Sri Lanka, the health unit system seldom utilized curative medicine. Rather it undertook the usual duties of a public health department in a tropical country, including health education, general sanitation, collection of vital statistics, study and control of preventable disease, vaccination, maternal and child welfare, and school hygiene inspection. ${ }^{70}$ The main objective of the health unit program in Sri Lanka was to prevent infectious disease or, more specifically, to deal with the most basic sanitary problems in the country. The only curative work that health units undertook were the treatment for hookworm infection and malaria through local dispensaries.

An equally important aspect of the health unit program was its substantially low per capita cost to the health care budget. The cost of health unit works for 1933 was about Rs. 240,205 (about \$ 81,000). This represented about 3 percent of the annual budget of the Department of Medical and Sanitary Services. The average per capita cost of health unit work was about Rs. 1.03 (less than \$ .50). ${ }^{71}$ The regular public health and sanitary work of health units were financed mainly by the government and the local authorities (Municipal/Urban Councils) of the district. It is important to note that the IHB did not undertake direct financial contributions to the health unit program. Its financial support was limited to what it described as "special circumstances" such as an unexpected shortfall of government funding for established programs, the need for recruiting additional personnel for specific programs, and the creation of "special projects" by the representatives of the IHB.

70 Uragoda, op.cit., p. 163.

71 RAC, Annual Report on Health Unit Work, p. 3, 1933. RG. 5, Se. 3, Box 192. 
One of the most important special projects that the IHB financed was the training of public health workers for Sri Lanka and other South and South-East Asian countries. For example, from the beginning the Kalutara health unit became the model for all the other health units established in Sri Lanka and elsewhere in Asia. Consequently, the Kalutara health unit was chosen as the training centre for public health personnel. ${ }^{72}$ In 1933, for example, as part of the IHB's campaign to expand the health unit concept in Asia, a group of 18 medical officers of health and public health nurses from India, Burma, and Java was invited to Kalutara for up to six months training on disease control and health education. In recommending a grant for a special project at the Kalutara health unit, Dr Jacocks wrote, "Kalutara has been, and continues to be, the chief training center for the East. Without the facilities, which it offers our rural work would be immeasurably handicapped." ${ }^{, 3}$ The importance of the Kalutara health unit as a training centre of public health personnel in Sri Lanka grew rapidly during the post-colonial period, when Sri Lanka's health infrastructure began to expand. The Kalutara health unit was expanded and named as the Institute of Hygiene in 1966. It was renamed in 1979 as the National Institute of Health Sciences becoming the premier public health training facility in the country. ${ }^{74}$

The health unit work must also be understood in terms of Sri Lanka's long-term public health achievements. Although it ranks today among the world's middleincome countries, Sri Lanka's record of public health achievements has often been compared to that of industrialized Western nations. High life expectancy at birth (75 years in 2010 estimated) and low mortality rates (5 per 1000) on the island approach the level of high-income countries. ${ }^{75}$ These achievements, no doubt, are the result of a host of public health and social programs that were introduced during the last seventy-five years. In 1952, commenting on the Sri Lanka's development achievements, for example, the International Bank of Reconstruction and Development (later World Bank) argued that insofar as it marked the beginning of the IHB's involvement in public health in Sri Lanka, the inauguration of the hookworm campaign in 1916 was "an important landmark in the public health services of the country." ${ }^{76}$ With the establishment of the first health unit in 1926, the curative and preventive services were unified under one administration. In 1931, the Departments of Local Government and Health were brought under

72 RAC, Ceylon, Kalutara Health Unit Designation for Two Years, p. 1, 1934, RG. 1.1, Se. 462, Box 1.

73 RAC, Kalutara Health Unit, Ceylon, A memo from W. P. Jacocks to V. Heiser, May 3, pp. 1-2, 1933, RG. 1.1, Se. 462, Box 1.

74 Ministry of Health, National Institute of Health Sciences, Kalutara, Sri Lanka, 1993, pp. $1-5$.

75 World Bank, World Development Indicators, Washington DC. 2010.

76 International Bank of Reconstruction and Development, The Economic Development of Ceylon, Baltimore, 1952, Part II, p. 127. 
one Ministry by giving greater responsibility to the local administration for public health matters. The administrative changes brought by the health unit program laid a solid foundation for the development of long-term preventive and curative health services in the country. ${ }^{77}$

Today, every Sri Lankan has access to a primary health care hospital within a radius of two miles. Unlike in most other developing countries, the problem of access to basic health care "virtually does not exist in Sri Lanka." ${ }^{78}$ A recent report by the WHO points out that Sri Lanka's success story of health achievements is, in large measure, due to its early start with a solid foundation for "equitable" and "community-based" approach to primary health care. The report specifically acknowledged the "equality of access" to health and education at all levels for both men and women as one of the core principles of national health priorities, and development policies in Sri Lanka that has contributed to outstanding health indicators. ${ }^{79}$ Undoubtedly, the health unit system, which was the forerunner to Sri Lanka's continuing commitment to progressive health policies and development strategies, could easily be adopted by other developing countries.

Soma Hewa is an Adjunct Professor at Queen's University, Kingston, Ontario, Canada.

77 Marga Institute, Intersectoral Action for Health: Sri Lanka Study, Colombo, 1984, p. 23; Uragoda, op.cit., p. 163.

78 WHO, Health Care in South-East Asia, New Delhi, 1989, p. 191.

79 WHO, Report of the Commission on Social Determinants of Health, Closing the gap in a generation: Health equity through action on the social determinants of health, Geneva, 2008, pp. 33, 113, 138 and 195. 


\section{References}

Balasingham, SW, The Administration of Sir Henry Ward, Governor of Ceylon, 1855-60 (Tisara Prakasakayo, Dehiwala, Sri Lanka, 1968).

Bell, DE, "Introduction," Social Science and Medicine, 14C, (1980), pp. 63-65.

Editorial, British Medical Journal, 1, (1927), p. 538.

Chellappah, SF and W. P. Jacocks, Guide to Health Unit Program, Preface to the first edition (Colombo, 1936).

Cueto, M, "The Origins of Primary Health Care and Selective Primary Health Care," American Journal of Public Health, 94(11) (2004), pp. 1864-1874.

Editorial, "Reports of Societies, The Malaria Epidemic in Ceylon," British Medical Journal, 1935, pp. 1015-1017.

Editorial, "Is there hope for South Asia? Yes, if we can replicate the models of Kerala and Sri Lanka," British Medical Journal, 328 (April 2004), pp. 777778.

Halstead, SB, J. A. Walsh and K. S. Warren, (eds.) Good Health at Low Cost: Proceedings of a Conference at the Bellagio Conference Centre, Italy, 29 April to 3 May 1985 (Rockefeller Foundation, New York, 1985).

Harrison, G, Mosquitoes, Malaria and Man: A History of Hostilities since 1880 (E. P. Dutton, New York, 1978).

Hewa, S, "The Hookworm Epidemic on the Plantations in Colonial Sri Lanka," Medical History, 38(1) (1994), pp. 73-90.

Hewa, S, Colonialism, Tropical Disease and Imperial Medicine: Rockefeller Philanthropy in Sri Lanka (University Press of America, Lanham, MD, 1995).

International Bank of Reconstruction and Development, The Economic Development of Ceylon (Baltimore, 1952, Part II).

IRIN, Sri Lanka: on track to eliminate malaria, UN office for the coordination of humanitarian affairs, 2008.

Johnson, BLC, South Asia, Selective Studies of the Essential Geography of India, Pakistan and Ceylon (Barnes and Noble, New York, 1971).

Jones, M, "The Ceylon Malaria Epidemic of 1934-35, A Case Study in Colonial Medicine," Social History of Medicine, 13(1) (2000), pp. 87-109.

Knighton, W, Forest Life in Ceylon (London, 1854).

Marga Institute, Intersectoral Action for Health: Sri Lanka Study, Colombo, 1984.

Ministry of Health, National Institute of Health Sciences, Kalutara, Sri Lanka, 1993.

Pampana, EJ, "Effects of Malaria Control on Birth and Death Rates," in Proceedings of the World Population Conference (United Nations, New York, 1954). 
Perera, M, Sri Lanka Study of Health Volunteers, International Review of Community Health Workers-Policy and Practice, Marga Institute (Colombo, 1987).

Stapleton, DH, "Technology and Malaria Control, 1930-1960: the career of Rockefeller Foundation engineer Frederick W. Knipe," Parassitologia, 42(1-2) (2000), pp. 59-68.

Stapleton, DH "Historical Perspectives on Malaria: The Rockefeller Anti-malaria

Strategy in the $20^{\text {th }}$ Century," Mount Sinai Journal of Medicine, 76 (2009), pp. $468-73$.

Uragoda, CG, A History of Medicine in Sri Lanka-from the earliest time to 1948. Sri Lanka Medical Association, Colombo, 1987.

Walsh, JA and K. S. Warren, "Selective Primary Health Care: An Interim Strategy

For Disease Control in Developing Countries," Social Science and Medicine, 14C (1980), pp. 145-163.

Warren, KS, "The Evolution of Selective Primary Health Care," Social Science and Medicine, 26(9) (1988), pp. 891-8.

Warren, KS, "The Alma-Ata Declaration: Health for All by the Year 2000?" Britannica Book of the Year, Encyclopedia Britannica, Inc. (Chicago, 1990), pp. 21-30.

WHO Primary Health Care. Report of the International Conference on Primary Health Care (Geneva, 1978).

WHO, Targets for Health for All by the Year 2000, ALMA-ATA: Geneva, 1978.

WHO, Health Care in South-East Asia (New Delhi, 1989).

WHO, Report of the Commission on Social Determinants of Health, Closing the gap in a generation: Health equity through action on the social determinants of health (Geneva, 2008).

Wickramasuriya, GAW, Malaria and Ankylostomiasis in the Pregnant Women (London, 1936).

Williams, G, The Plague Killers, Charles Scribner (New York, 1969).

World Bank, World Development Indicators (Washington DC. 2010).

\section{Rockefeller Archive Center (RAC)}

Relief and control of hookworm disease in Ceylon, 1918, Record Group (RG.) 5, Series (Se.) 2, Box 47.

Relief and control of hookworm disease in Ceylon, 1920, RG. 5, Se. 2, Box 47.

European Planting Community in Regard to Medical Aid and Sanitation, 1921. RG. 5, Se. 2, Box 47.

Summary Report, Anchylostomiasis Campaigns-Ceylon, 1921. RG. 5, Se. 3, Box 193. 
A Program for the Control of Malaria in Ceylon, M. E. Barnes and Paul F. Russell, Colombo, 1925, RG 5, Se. 2, Box 48

W. P. Jacocks, Preliminary Report on Health Units, 1926, RG. 462, Se. 2, Box 48. First Annual Report of the Health Unit Kalutara Badda, 1926. RG. 5, Se. 3, Box 198.

1926 Preliminary Report on Health Units.

Anchylostomiasis Campaigns, Ceylon, A Letter to V. Heiser from W. P. Jacocks, November 28, 1927, RG 1.1, Se 3, Box 1.

The First Annual Report of the Health Unit Matara, 1928. RG. 5, Se. 3, Box 201. Annual Report on Health Unit Work, 1928. RG. 5, Se. 3, Box 199.

Division of Sanitary Engineering, Ceylon, Report on Ceylon for 1929, 1930, RG. 5, Se. 2, Box 47. Annual Report: Health Unit Work, 1928, RG. 5, Se. 3, Box 199. Annual Report on the Health Unit Work, 1929. RG. 5, Se. 3, Box 200. Annual Report on Health Unit Work, 1929. RG. 5, Se. 3, Box 198. Annual Report: Weudawili Hatpattu, 1930. RG. 5, Se. 3, Box 200. Annual Report, Health Unit Matara, 1930. RG. 5, Se. 3, Box 201. The Report on the Work of the Trincomalee Health Unit, 1930, RG. 5, Se. 3, Box 201.

Ceylon Health Units, A Summary of Health Unit Information for the Year 1930, 1931, RG. 1.1, Se. 462, Box 1. 1932 Maternity and Child Welfare, Annexure (M), RG. 462. Annual Report on Health Unit Work 1933. RG. 5, Se. 3, Box 192.

Kalutara Health Unit, Ceylon, A memo from W. P. Jacocks to V. Heiser, May 3, 1933, RG. 1.1, Se. 462, Box 1.

Ceylon, Kalutara Health Unit Designation for Two Years, 1934, RG. 1.1, Se. 462, Box 1.

Malaria Eradication in Ceylon, 1948, RG. 5, Se. 2, Box 47.

\section{Sri Lanka National Archives}

Despatch No.6, April 21, 1847, 5/34.

Report on the Malaria Epidemic in Ceylon in 1934-35, Sessional Paper 23, Colombo, 1935, p. 5. 